\author{
ANNALS OF “DUNAREA DE JOS” UNIVERSITY OF GALATI \\ MATHEMATICS, PHYSICS, THEORETICAL MECHANICS \\ FASCICLE II, YEAR XI (XLII) 2019, No. 2
}

DOI: https://doi.org/10.35219/ann-ugal-math-phys-mec.2019.2.08

\title{
PHARMACEUTICAL COMPOUNDS AND ENDOCRINE DISRUPTORS IN AQUATIC ENVIRONMENTS: ECOTOXICOLOGICAL EFFECTS AND ANALYSIS METHODOLOGY
}

\author{
Elena Enachi ${ }^{1}$, Gabriela Elena Bahrim ${ }^{1}$, Antoaneta Ene ${ }^{2,3^{*}}$ \\ ${ }^{1}$ Faculty of Food Science and Engineering, ,,Dunărea de Jos” University of Galati, Romania \\ ${ }^{2 *}$ Faculty of Sciences and Environment, Department of Chemistry, Physics and Environment, „Dunărea de Jos” \\ University of Galati, Romania \\ ${ }^{3}$ INPOLDE interdisciplinary research network, ReForm multidisciplinary Platform, Dunarea de Jos \\ University of Galati, Faculty of Sciences and Environment, 111 Domneasca St., 800201 Galati, Romania \\ *Corresponding author: aene@ugal.ro
}

\begin{abstract}
Currently, there is an urgent need to strengthen the scientific knowledge and to adopt the most appropriate means to monitor the emerging pollutants in different water and wastewater sources and at the same time to evaluate their actions and risks on human health. Emerging contaminants (ECs) or pollutants (EPs) are, in the widest sense, any synthetic or natural compound or any microorganism that is not ussualy found or monitored in the environment, with potentially known or suspected ecotoxicological and negative effects on human health. Among the EPs, pharmaceuticals and personal care products are well-known for their adverse reactions. Among pharmaceutical compounds, antibiotics such as amoxicillin, cefuroxime, ciprofloxacin etc. are recognized as a class of emerging contaminants due to the fact that these compounds have been massively administered to humans and animals and usually persist in the environment through a complex vicious cycle of biotransformation and bioaccumulation. Two other classes of emerging pollutants - endocrine disruptors and contraceptives - are compounds that can mimic or interfere with the normal function of hormones in the body. These substances can turn on, stop or alter the signals that hormones carry, which can in turn affect the normal functions of the body. As regards of pharmaceuticals, a set of programs has been launched in EU Member States to reduce the risks that they pose to human health and the environment, here including several comprehensive monitoring programs. In the light of the new regulations and the concerns regarding the presence of pharmaceuticals in the aquatic environment, the experimental design is a very important step in achieving the detection of selected compounds, such as antibiotics, anti-inflammatory, endocrine disruptors and contraceptives, in the Romanian aquatic natural ecosystems. In this paper we highlighted the ecotoxicological effects of selected ECs and EPs, as well as the proposed methodology for their analysis. Part of this review was presented at the MONITOX International Symposium „Deltas and Wetlands”, Tulcea, Romania, 15-17 September, 2019.
\end{abstract}

Keywords: emerging pollutants, pollution of aquatic ecosystems, pharmaceuticals, antibiotics, endocrine disruptors, contraceptives

\section{INTRODUCTION}

The emerging contaminants (ECs) or pollutants (EPs) represent, in a broad sense, any synthetic or naturally-occurring or chemical type of substance or any microorganism that is not usually monitored by any monitoring agency or regulated in the environment, with potentially known or presumed ecological and human health side effects. 
These types of emergent contaminants comprise mainly chemical compounds found in pharmaceuticals, personal care products, pesticides, industrial and household products, surfactants, industrial additives and solvents.

Many of these contaminant substances are perpetually used and released back into the environment at very small concentrations, which may cause acute or in the long run chronic toxicity, endocrine disruption in humans and aquatic wildlife and the development of pathogen bacterial resistance.

Numerous scientific reports and studies have shown a variable number of sources and routes for the emergence of emerging contaminants, and in recent years this intensive research has been conducted in order to highlight their adverse effects upon the environment [1]. As each targeted area has its own specific climate, topography and environmental interactions, so they have specific contaminants in that region.

Predominantly, these contaminants or pollutants are produced through an on-field route such as wastewater treatment plant, soil, wastes of a medical facility, poorly treated raw materials, animal and livestock and several industries (Fig.1).

The wastewater treatment plants are also a source of pharmaceutical contamination as they are designed to eliminate the easily biodegradable nitrogenous, carbon and phosphorous compounds present in the wastewater [2].

These types of chemicals may exhibit a cytotoxic activity and in term they can cause obesity, diabetes, cardiovascular and reproductive disorders or even lead to other disorders like cancer and neoplasms.

Recently, the availability of a sensitive instrumental method for the detection and identification of these chemical compounds has enabled different studies on the emergence of many contaminants in the environmental systems at even at trace concentrations [3,4].

The fate and the potential effects and risks of these compounds upon ecosystems and human health at such concentrations have been a real concern for the scientific world. This notorious interest justifies the large number of reviews and scientific articles regarding the analytical determination [5], the occurrence, distribution and risks of emergent contaminants in the environment, especially in the aquatic compartments [4]. Nonetheless, little is currently known about the potential toxicological and ecological impact of these types of substances on the aquatic ecosystems $[4,6]$.

The environmental analysis of these types of emergent compounds such as antibiotics, endocrine disruptors, contraceptives focuses on the samples' preparation, analyte stability, degradation and matrix effects.

These compounds and their metabolites are continually discharged into the natural environment so that many studies considered the fact that some of these pharmaceuticals with low molecular weight quickly dissolve into the water bodies and hence results the persistence and recalcitrance of these emergent contaminants and their isomers [7].

In term, due to the very high incidence rate of these compounds in the environment, the EU, EMEA and CDC developed a series of water quality regulations [8-12]. The EU Directive 2013/39/EU sets the environmental quality standards (EQS) for a list of substances of concern (antibiotics excluded) in the surface water and biota across EU due to their widespread use and their high concentrations in rivers, lakes, transitional and coastal waters [13].

Consequently, this research comprises and reviews the most recent data regarding the incidence of these emergent contaminants such as antibiotics, endocrine disruptors and contraceptives, their detection and identification in the aquatic environment and their ecotoxicological effects in different European areas such as the Black Sea basin, Danube Delta, Danube River etc..

Nonetheless, further scientific studies that concerns their effects on the environmental and human health is required in order to provide the necessary means to the competent authorities that will have to establish effective and adequate monitoring strategies and the most appropriate regulation for the targeted substances. 


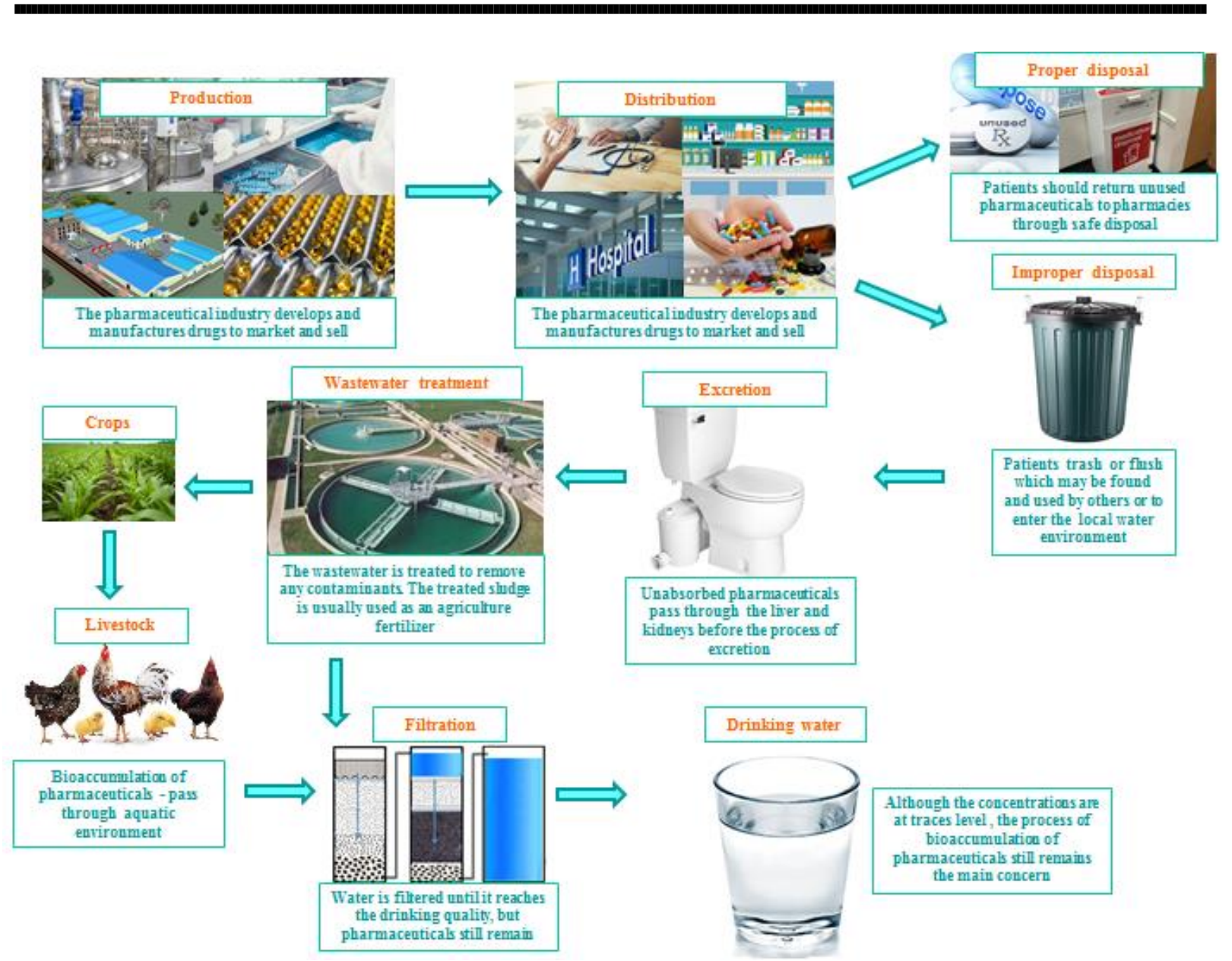

Fig. 1. Environmental pollution with pharmaceutical compounds

\section{STATE OF THE ART}

In Romania, the most important aquatic area are represented by Danube River, Danube Delta and the Black Sea basin. The Danube River is considered to be the second largest European waterway, being one of the most natural, historical, cultural and economically important rivers of Europe. The length of this river is approximately $2826 \mathrm{~km}$, and its basin drains into 19 countries from the Black Forest (Germany) to the Black Sea (Romania). The Danube Delta, which is situated between the three main Danube branches, Sfântul Gheorghe, Sulina and Chilia covers around 4560 $\mathrm{km}^{2}$, and has a buffering role between both of the systems: the Danube River and the Black Sea [14]. Besides Romania, another country near to the Black Sea basin that reported the incidence of such compounds is Greece. Regarding the occurrence of the aforementioned pharmaceutical compounds, Arditsoglou and Voutsa [15] managed to investigate the occurrence of some contraceptives and endocrine disruptors (nonylphenol, octylphenol, their mono- and diethoxylate oligomers, bisphenol A, estrone, 1,7a-estradiol, 1,7b-estradiol, estriol, mestranol and 1,7a-ethynylestradiol) in the area of the Thermaikos Gulf, Northern Aegean Sea, Greece. All of the phenolic compounds were detected in all of the samples, with nonylphenol and its ethoxylates being the dominant pollutants.

Borova et al. [16] assessed the presence of 68 pharmaceutical compounds from samples collected from five wastewater treatment plants in Santorini, Aegean Sea, Greece. The undertaken study took into consideration the development and validation of a highly sensitive analytical method for the simultaneous detection of 68 compounds, including illicit drugs (opiates, opioids, cocaine compounds, amphetamines, and hallucinogens), psychiatric drugs (benzodiazepines, barbiturates, anesthetics, antiepileptics, antipsychotics, antidepressants, and sympathomimetics), and selected 
human metabolites from the wastewaters by high performance liquid chromatography coupled to tandem mass spectrometry (LC-MS/MS). The authors obtained low detection limits between 0.04 and $10.0 \mathrm{ng} / \mathrm{L}$ for $87 \%$ of the compounds, thus allowing a dependable and accurate quantification of the analytes at trace level. Thirty-two out of 68 compounds were detected in all the samples in the range between $0.6 \mathrm{ng} / \mathrm{L}$ (for nordiazepam), 6,822 ng/L (for carbamazepine) $0.4 \mathrm{ng} / \mathrm{L}$ (for $9-\mathrm{OH}$ risperidone) and 2,200 $\mathrm{ng} / \mathrm{L}$ (for carbamazepine).

Chiţescu et al. [13] studied the occurrence of 67 pharmaceutical and antifungal residues in the Danube river on the Romanian territory by using a solid-phase extraction (SPE) and a LC-Q Exactive Orbitrap high resolution MS in both full scan (FS) MS and targeted MS/MS modules. To detect all the targeted 67 pharmaceutical compounds, a single-laboratory validation procedure was carried out in a FSMS mode by evaluating the selectivity, sensitivity, linearity, precision and accuracy. The employed method displayed a satisfactory analytical performance. Twenty Danube water samples and three of the main tributaries were collected in the months of May, July, August and October 2014. The chromatographic analysis of the selected water samples revealed the presence of 23 compounds such as diclofenac, indomethacin, sulfamethoxazole, tylosin, carbamazepine, ketoprofen, piroxicam, together with several antifungals like thiabendazole and carbendazim. Carbamazepine was detected in 17 samples, the maximum concentration being $40 \mathrm{ng} / \mathrm{L}$. The highest concentration was registered for an anti-inflammatory drug, namely diclofenac, whose concentration was $166 \mathrm{ng} / \mathrm{L}$ [13].

Out of the 67 targeted compounds, 23 pharmaceuticals and antifungals compounds (34\%) were detected in the water samples. Sulfamethoxazole, an antibiotic used combined to trimethoprim, was the most frequently detected in 18 out of the 20 collected samples. The concentration ranged from 2.5 to $30 \mathrm{ng} / \mathrm{L}$. Moreover, the macrolides tylosin and tiamulin were detected in 9 and 7 water samples, respectively, at concentrations between 11.1 and $39 \mathrm{ng} / \mathrm{L}$ for tylosin and 3.1 to $5.6 \mathrm{ng} / \mathrm{L}$ for tiamulin. Regarding the quinolone class, ciprofloxacin was detected only in two samples. For the sample collected from the Argeș river, the concentration was $6 \mathrm{ng} / \mathrm{L}$. Another targeted compound, carbamazepine, was detected in 17 samples, the maximum concentration being $40 \mathrm{ng} / \mathrm{L}$. From the NSAID class, diclofenac, indomethacin, naproxen, piroxicam, and ketoprofen were all identified in the selected samples. The highest recurrence rate, 12 samples, and concentration was detected for diclofenac. The highest concentration was $166 \mathrm{ng} / \mathrm{L}$ whereas ketoprofen was detected in 7 samples with the highest concentration of $57.5 \mathrm{ng} / \mathrm{L}$ [13].

Papageorgiou et al. [17] assessed in the aquatic environment the presence of fifty five pharmaceutical and personal care compounds belonging to 14 therapeutic classes (11 antibiotics, 11 analgesics/anti-inflammatories, 5 beta-blockers, 8 antidepressants, 1 phosphodiesterase type $\mathrm{V}$ inhibitor, 2 steroids, 5 antihistamines, 6 lipid regulators, 1 psychomotor stimulant, 1 diuretic, 1 betaagonist, 1 calcium channel blocker, 1 UVA/UVB absorbent and 1 disinfectant). The sampling was carried out in Volos, Greece, between 2013 and 2014. Out of the 55 targeted compounds, the following compounds meloxicam, tolfenamic acid, gemfibrozil, clofibric acid, fenofibrate, atorvastatin, budesonide, amoxicillin, olanzapine, bupropion, nifedipine, duloxetine, ranitidine, pindonol, nadolol, methdilazine, salbutamol and triclosan were not detected in any of the investigated samples. In the influents, the most dominant compounds were paracetamol (100\%), trimethoprim $(100 \%)$, carbamazepine $(100 \%)$, caffeine $(100 \%)$, ampicillin $(95.8 \%)$, fluvoxamine $(95.8 \%)$, atenolol (95.8\%), cetirizine $(91.7 \%)$, sulfamethoxazole $(83.3 \%)$ and salicylic acid $(70.8 \%)$, respectively.

Moldovan et al.[18] assessed the presence of various anthropogenic organic pollutants along the transboundary Prut River, the second longest tributary of the Danube river, in order to provide useful information regarding the data on the environmental contamination in the eastern European surface waters. In general, the concentrations of the pharmaceuticals were identified as being lower than $20 \mathrm{ng} / \mathrm{L}$, the exception being the following compounds: metformin (100-240 ng/L), 4acetamidantipyrine (75-210 ng/L), gabapentin (140 ng/L), propyphenazone (117 ng/L), phenazone (antipyrine) (15-73 ng/L), and atenolol (8.4-40 ng/L). Concerning the detection of personal care products compounds, two polycyclic musks, galaxolide and tonalide, were detected at an average concentration of $117 \mathrm{ng} / \mathrm{L}$ and $19 \mathrm{ng} / \mathrm{L}$, respectively. Compared to other river systems in Europe, the levels determined in the Prut river were lower. 
Fekadu et al. [19] studied the detection of 71 targeted pharmaceutical compounds from samples collected all over Europe and confirmed the presence of many of these compounds all over Europe's water ecosystems. From all these pharmaceutical compounds, the researchers highlighted the presence of endocrine disruptors, contraceptives and steroidal hormones. In France, Czech Republic, Italy, Germany, Luxembourg and Spain aquatic environments, estrone was reported in a concentration level ranging from $0.1 \mathrm{ng} / \mathrm{L}$ to $69 \mathrm{ng} / \mathrm{L}$ whereas progesterone in a range between 0.23 $\mathrm{ng} / \mathrm{L}$ and $13.7 \mathrm{ng} / \mathrm{L}$ in France and Hungary. Testosterone and estriol were found up to $3 \mathrm{ng} / \mathrm{L}$ and 2.38 ng/L, respectively. In Italy and France $1,7-\beta$-estradiol was detected in concentrations between 0.33 $\mathrm{ng} / \mathrm{L}$ to $5 \mathrm{ng} / \mathrm{L}$.

\section{ANALYSIS METHODOLOGY}

Each water sample is collected in different volume flasks from the targeted areas of interest, namely the Black Sea Basin, Danube Delta and Danube River (Fig. 2). The sample sites are selected in order to provide the most relevant data regarding the contamination with pharmaceutical compounds (antibiotics, contraceptives and endocrine disruptors).

In order to concentrate the water samples, a solid phase extraction is undertaken in order to clean the samples by using cartridges like Strata X, $200 \mathrm{mg} / 6 \mathrm{~mL}$, reversed-phase, SPE cartridges (Phenomenex, USA). The cartridges are previously preconditioned with methanol followed by Milli Q water.
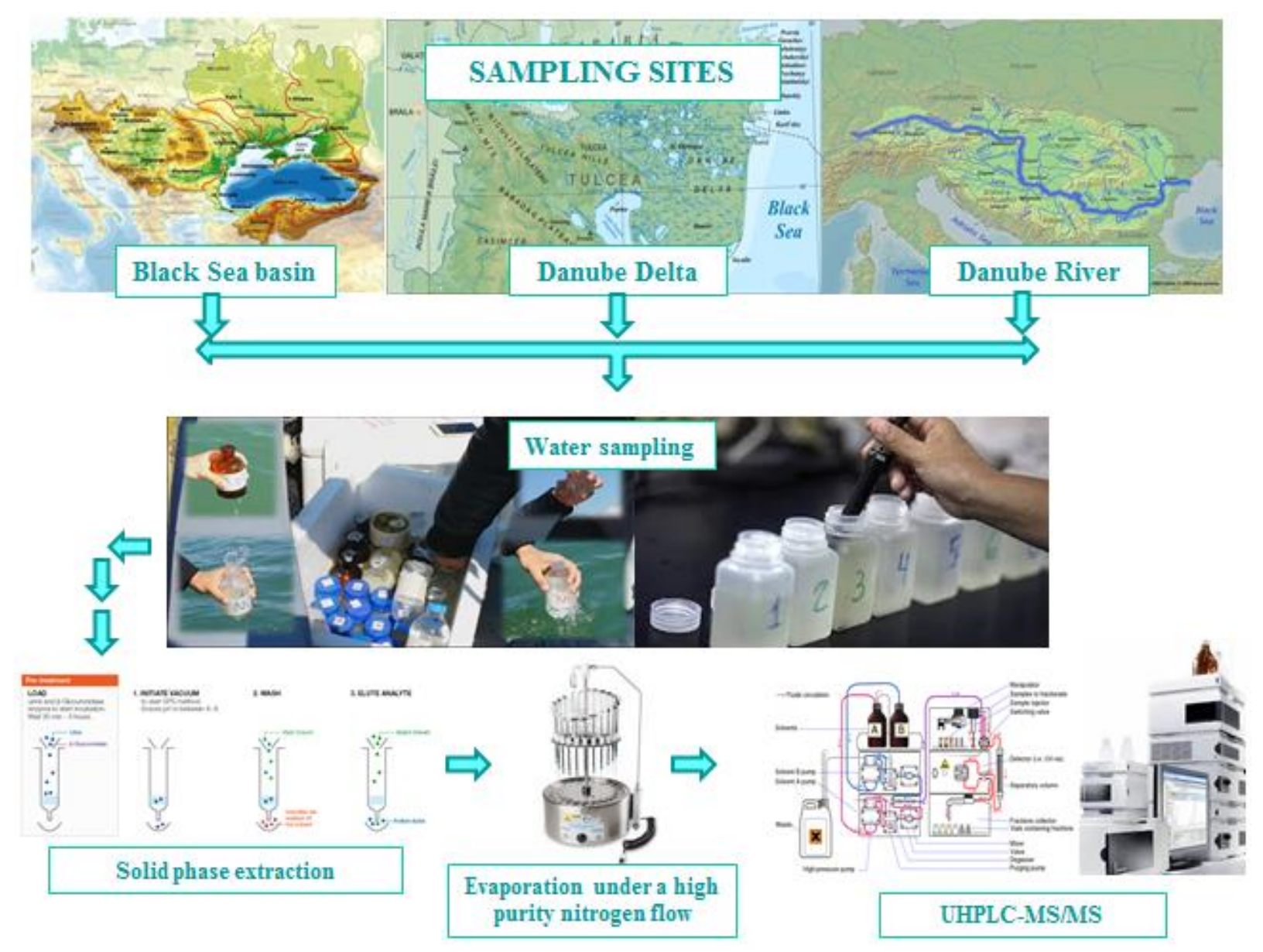

Fig. 2. Scheme of sampling, detection and identification of the targeted pharmaceutical compounds by Ultra High Performance Liquid Chromatography coupled with Mass Spectrometry (UHPLC-MS/MS) at Dunarea de Jos University of Galati, Romania 
Before loading the cartridge, a volume of $\mathrm{Na}_{2}$ EDTA solution is added to a certain volume of water and the $\mathrm{pH}$ is adjusted to the value of 3.0 with acetic acid. After the sample's application, the cartridge is washed with Milli Q water, followed by a solution of $30 \%$ methanol/water (v/v) and dried under vacuum for 5 minutes.

The analytes are afterwards eluted with methanol. The elute is concentrated by evaporation under a high purity nitrogen flow, in a water bath, and redissolved in methanol and water [13].

For the detection and identification of the targeted pharmaceutical compounds (Fig.2), usually the method involves the use of a UHPLC-MS/MS equipment. In order to determine the most efficient method for detection of this type of pharmaceutical compounds, several parameters must be taken into consideration. Before the injection of the samples, the application of a gradient over a $\mathrm{C} 18$ or a $\mathrm{C} 8 \mathrm{U}$ HPLC column is undertaken. A flow rate between $0.4-0.5 \mathrm{~mL} \mathrm{~min}^{-1}$ is set for the separation of the selected compounds in the U-HPLC system. The mobile phase usually consists of two or more

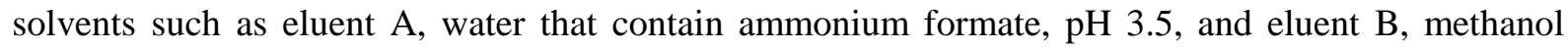
(also containing ammonium formate, $\mathrm{pH} 3.5$ ).

The column temperature is set at around $40^{\circ} \mathrm{C}$ and the injection volume at $10 \mu \mathrm{L}$. The detection of the compounds is performed with a mass spectrometer under different parameters as highlighted by many researchers over the undertaken studies.

For the compounds of interest, a m/z scan range between 130-1000 is chosen. In addition to the full scan acquisition method, for confirmatory purpose, a targeted MS/MS analysis is performed using a mass inclusion list and the expected retention times of the targeted analytes.

\section{ECOTOXICOLOGICAL EFFECTS}

The high ecological risk of these compounds whether they are antibiotics, contraceptives or endocrine disruptors in the aquatic environment has been regarded as a growing concern all over the world. Antibiotics, as bioactive molecules, are especially used to fight against pathogenic or bad bacteria. However, in the environment non-targeted organisms are unavoidably exposed to these residues and their metabolites. The primary producers and decomposers, which are imperative for a sustainable ecosystem, are vulnerable in front of the presence of these emergent contaminants.

Thereupon, antibiotics can disrupt in the aquatic environment many vital ecosystem processes. These potential ecotoxicological effects are difficult to predict, especially in complex matrices. The antibiotics' acute or chronic toxicity has been assessed by several standard ecotoxicity assays that were undertaken on different trophic levels organisms, such as bacteria, algae, invertebrates, and fish.

Generally speaking, the toxicity studies on antibiotics in the aqueous environment only take into account each individual pharmaceutical compound. Since antibiotics emerge into the aquatic environment as a mixture, additive or synergistic effects should also be considered in the environmental risk assessments [4].

Overall, the undertaken studies demonstrated that any type of antibiotic can become toxic to non-targeted organisms, or to pose a potential ecological risk for the aquatic organisms taken into account the nowadays usage patterns. However, very few publications regard the ecotoxicity of antibiotics and their by-products so to assess and understand the real scenario [20].

Another course for the antibiotics to enter the aquatic ecosystems is by mixing the sewage waste that is incompletely biodegraded and the wastewater treatment plants least eliminated effluents. Also, the high rate of consumption also influences the emergence of antibiotics from veterinary and poultry, aquaculture and manure applications or by the improper disposal of unused antibiotics.

One of the most important issues of the pharmaceutical and medical industries is the antibiotic resistance (Fig. 3). This phenomenon, nowadays, spreads at the speed of light globally through the highest consumption rate ever registered.

Fluoroquinolones are frequently found in the hospital wastewater so that the studies showed that these types of antibiotics are more toxic to prokaryotes than eukaryotes, here including freshwater algae, fish and zooplankton and finally through the process of bioaccumulation they reach the human 
bodies. Recent studies also reported that antibiotics are taken up by crops that are irrigated with contaminated water, i.e., carrot, radish, corn and cabbage.

Worldwide, the antibiotic consumption data is insufficient because of its high variation regarding their prescription and administration. All the international data available on the antibiotic usage is estimated and approximated, since many countries do not declare their monitoring data, and hence the actual data remains unreported [4, 20, 21].

The antibiotics that are used in the veterinary and poultry industry further increase the reluctant mechanism of bacterial strains to survive under the antibiotic stress thus resulting in the evolution of multidrug-resistant bacteria. Studies on Bifidobacterium, Clostridium, Escherichia coli, Enterococcus and Lactobacillus clearly showed that their structural composition and metabolic activities are severely affected by antibiotics as these compounds play a crucial role in the ecology change particularly on the niche where the genetic transformations take place.

From all the antibiotic classes, sulfonamides and fluroquinolones are the most persistent in the aquatic environment followed by macrolides whereas aminoglycosides and $\beta$-lactams are the least persistent. Tetracyclines can also persist for a relatively long period in the absence of sunlight, at the expense of their mobility [20,21].

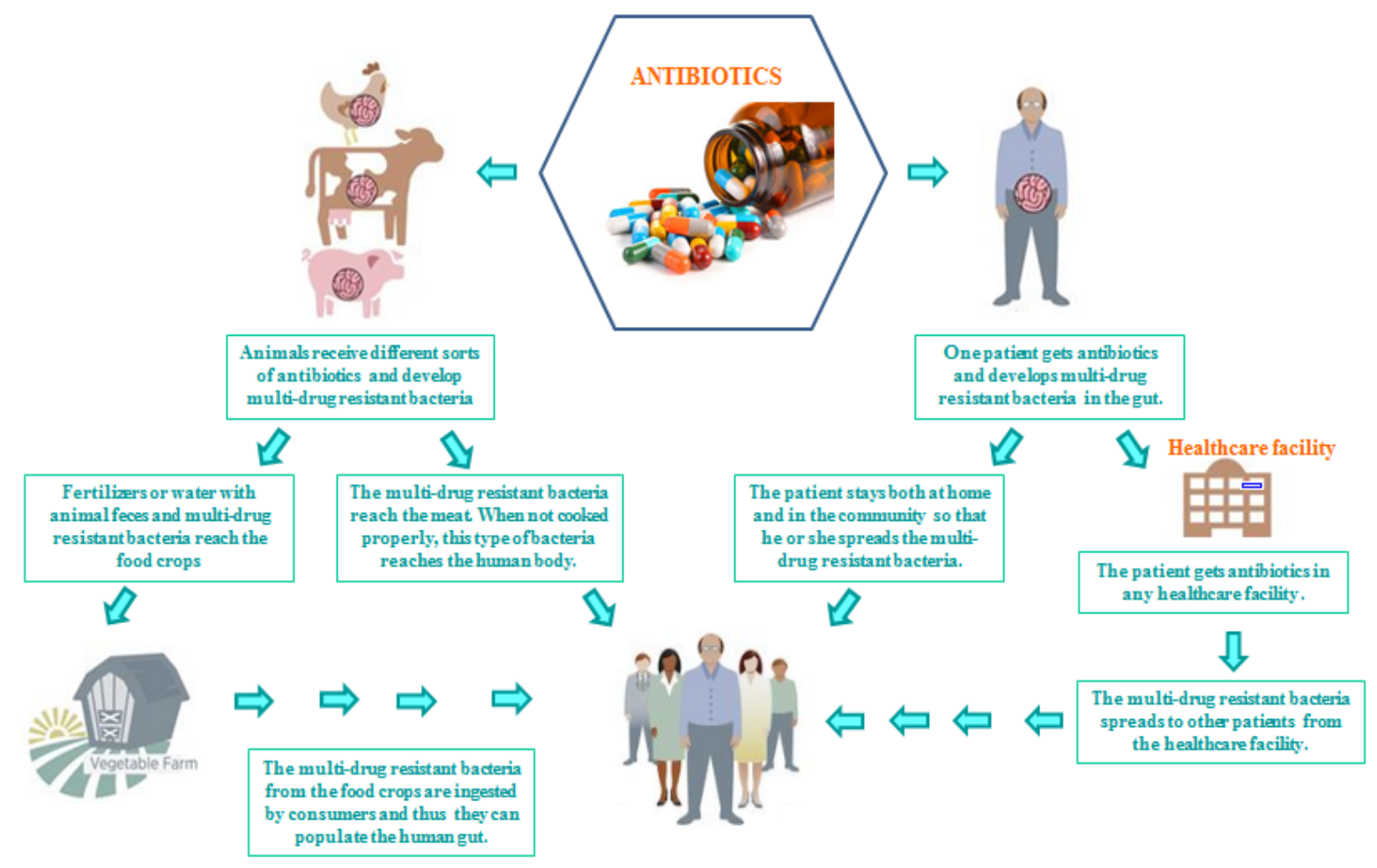

\section{Fig. 3. Antibiotic resistance occurrence}

Regarding the presence of endocrine disruptors and contraceptives (Fig. 4), estrogens like 1,7estradiol, estrone, estriol, ethinyl estradiol, drospirenone and levonorgestrel have been identified in the aquatic environment more and more often in the past few years. Maybe the most important concern regarding these contraceptive compounds is the very high density of animals which generate large amounts of manure, a significant source of hormones into the soil and surface water.

The presence of 1,7-estradiol, androstenedione, estrone, testosterone and progesterone (ranging from 5 to $250 \mathrm{ng} / \mathrm{L}$ ) was detected in the runoff from the feedlot's surfaces during a rainfall simulation after the animals were removed from the enclosures [22].

Similarly, numerous studies highlighted the presence of these natural and synthetic estrogens (estrone, 1,7-estradiol, and estriol), androgens (trenbolone) and progestagens (progesterone and melengestrol) in the rivers that are situated nearby the animal farms. 
In the contraceptive pills, the major synthetic hormones are progestins, with a release estimated to reach $700 \mathrm{~kg} / \mathrm{year}$. This environmental release may conduct to an estrogen overexposure of the human population and of the aquatic animals. At the same time, the environmental rates of progestins are not very well documented [23].

Generally, bisphenols act on the hormonal level by distorting the hormonal balance and inducing several estrogenic effects through the binding to estrogen-related receptors [24].

The bisphenol A was also reported to trigger an early sexual characteristics and obesity onset development. In males, the exposure to bisphenol A (between 1.53-2.22 $\mu \mathrm{g} / \mathrm{L}$ ) especially during the developmental stage resulted in feminization of the male fetuses, testicular and epididymis atrophy, alteration of sperm parameters, and the reduction of testosterone levels.

The most possible mechanism is that bisphenols usually induce a phosphorylation reaction which contributes to the activation of the P450 genes cytochrome (CYP gene) expression in both mRNA and protein levels, which finally results in the alteration of the normal sex hormone ratio [24, 25].

Many studies have shown that the overall effects of bisphenols, especially the A type, on the male reproductive system have shown to be more pronounced in the fetal period. In females, the high serum concentration of bisphenol A (1.53-2.22 $\mu \mathrm{g} / \mathrm{L})$ induces changes in the estradiol serum concentration, which results in a hormonal misbalance and in metabolic abnormalities such as early puberty, menstrual irregularities, endometriosis, higher implantation failure and ineffective gonadotropin fertility treatment.

The binding of the bisphenol A to the estrogen-related receptors has resulted in multiple negative outcomes due to its distortion of the hormonal balance $[24,26]$.

Several reports have also shown that bisphenol A displayed the alteration of the immune system through a multi-targeted approach. This compound caused the alteration of the genes transcription process thus exhibiting sex differences during the neonatal periods, which in the end resulted in the decrease of the sex genes expression. This factor had an immunomodulatory role and resulted in a compromised auto-inflammatory response and the deregulation of the immunoglobulin [24-26].

It was suggested that this emergent compound binds to the estrogen-related $\gamma$ receptor, which is strongly expressed in the mammalian brain development and promotes the differentiation and maturation of the fetal brains disorders.

In a research conducted lately to determine the effect of the bisphenol $\mathrm{A}$ analogue on the adrenocortical function, H295R, which is an angiotensin-II-responsive steroid-producing adrenocortical cell, was used as a toxicity comparison pattern. The results showed several inhibitory effects on the hormonal adrenocortical function [24].

Recent findings have indicated that bisphenol A induced an increased tumor necrosis factor (TNF $\alpha$ ) and conformational changes in the estrogen-related receptors. Moreover, the pathological outcomes concerning the exposure to bisphenols vary with the routes, concentrations and dosage.

The effects of the exposure on the glucose regulation have been extensively studied so that it was indicated that the exposure to a high level of bisphenols whether it's A or F, $(10-400 \mathrm{mg} / \mathrm{kg})$ caused oxidative stress and the disruption of pancreatic $\beta$-cell function which in term resulted in a glucose regulation process $[24,25]$.

Furthermore, the bisphenols exposure was tested on several mice and rats to better understand their effect on the insulin signaling in the brain. As a result it was discovered that, in the fetal mice ( 8 months of age), the insulin signaling including the insulin phosphorylated extracellular signal regulated the kinase protein and the glucose transporter, factors that were significantly decreased. Also, the hyper-insulinemia, glucose intolerance and insulin resistance were reported to be associated to the bisphenols exposures [24].

The bisphenol A exposure and its adverse effects on the cardiovascular system were studied and the reports suggested a possible relationship between the exposure and the hypertension condition that severely affects the cardiovascular system during a hypoxic event. Furthermore, the exposure affected the angiogenesis by stimulating the production of vascular endothelial growth factor, which 
resulted in an uncontrolled neovascularization and in the increase of the interventricular septal thickness [24-26].

Nonetheless, it was also reported that the exposure to bisphenols within a varying concentration of $1-250 \mu \mathrm{g} / \mathrm{mL}$, caused an increase of the calcium levels in incubated erythrocytes with the strongest effect noted for bisphenol $\mathrm{A}$ and bisphenol $\mathrm{F}$ which particularly resulted in the increase of the phosphatidylserine translocation in red blood cells and arrhythmias. The use of bisphenols in the production of polycarbonate plastics and epoxy resin has been also identified as an important contributor to the bisphenols pollution of the aquatic ecosystems [24-26].

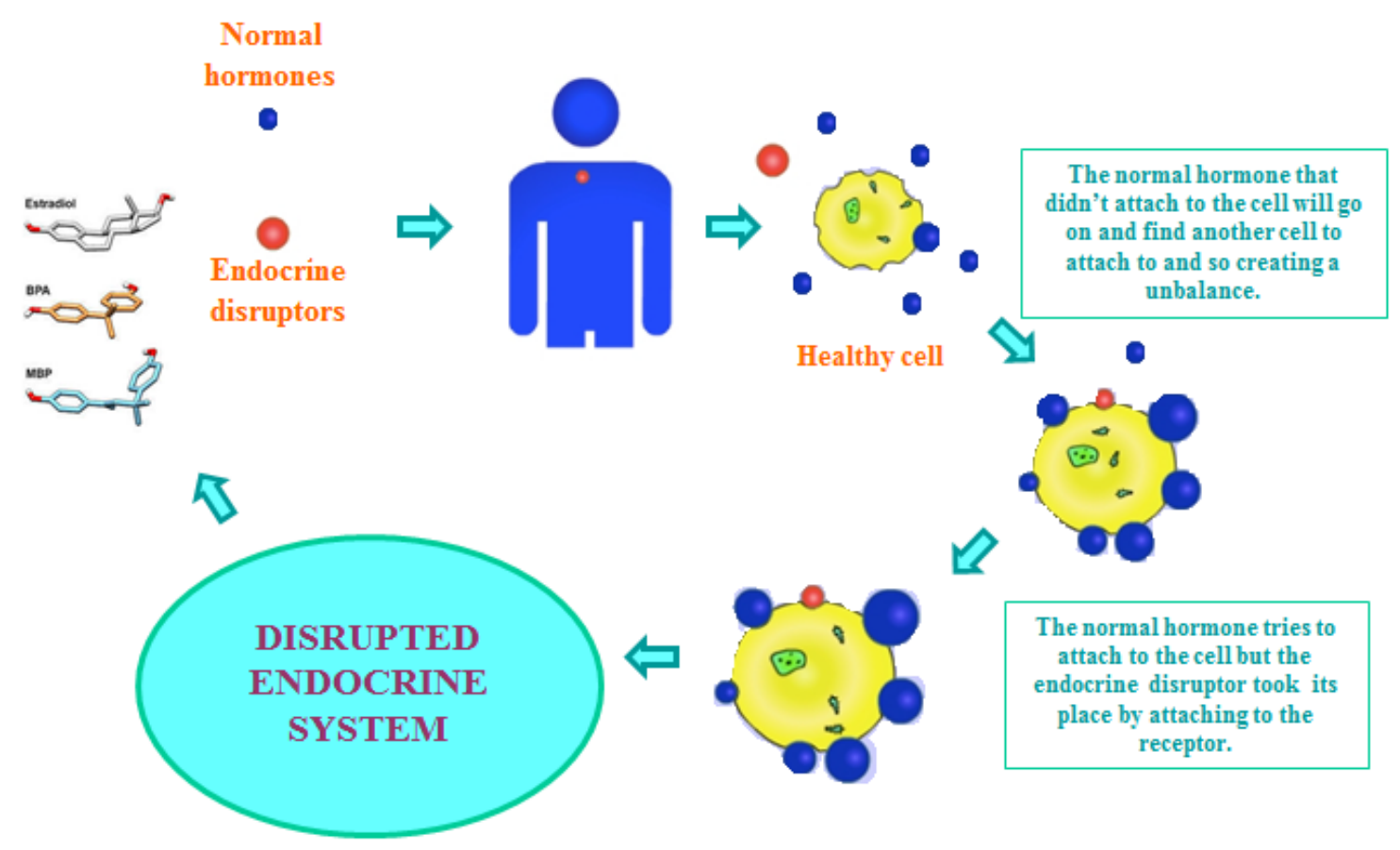

Fig. 4. Endocrine disruptors system

Despite the recent scientific advances on this topic, only small pieces of information are available to scientists to clearly understand the extent of the environmental contamination with pharmaceutical compounds and endocrine disruptors and their importance in terms of the overall risk $[4,21]$.

Future studies of ECs and EPs concentration in aquatic ecosystems of Black Sea Basin and Danube River and Danube Delta will be performed in the frame of MONITOX project, code BSB27 [27], using the methodology and the UHPLC-MS/MS experimental setup described in this paper.

\section{CONCLUSIONS}

The present review provided the most comprehensive information about the incidence and occurrence of pharmaceutical compounds in the European aqueous environment and also on the most modern investigation techniques that can be employed to detect these types of emergent contaminants. Depending on the pharmaceutical class and the environmental matrix, the typical concentrations range from $\mathrm{ng} / \mathrm{L}$ to $\mu \mathrm{g} / \mathrm{L}$. The highest concentration of these contaminants was detected into the effluents that are commonly discharged in rivers and seas natural aqueous environment. Furthermore, low concentrations of pharmaceutical compounds were also reported in the drinking water, a fact that highlights the exposure of Europeans to the uncontrolled and sub-therapeutic dosages via the environment. The monitoring of these types of compounds in the aquatic environments waters is crucial to assess the effects they induce on the natural ecosystem and on the human and animal health, as well as to improve the understanding of their ecotoxicological effects. 
Acknowledgement: This review study was supported by the Project with code BSB27 "Black Sea Basin interdisciplinary cooperation network for sustainable joint monitoring of environmental toxicants migration, improved evaluation of ecological state and human health impact of harmful substances, and public exposure prevention (MONITOX)", contract grant 105070/14.09.2018.

\section{References}

1. Rasheed, T., Bilal, M., Nabeel, F., Adeel, M., Iqbal, H.M., Environmentally-related contaminants of high concern: potential sources and analytical modalities for detection, quantification, and treatment, Environ. Int., in press, 2019.

2. Bilal, M., Rasheed, T., Sosa-Hernández, J., Raza, A., Nabeel, F., Iqbal, H., Biosorption: an interplay between marine algae and potentially toxic elements-a review, Marine Drugs 16 (2): 65, 1-16, 2018.

3. Farré, M., Kantiani, L., Petrovic, M., et al., Achievements and future trends in the analysis of emerging organic contaminants in environmental samples by mass spectrometry and bioanalytical techniques, J. Chromatogr. A. 1259, 86-99, 2012.

4. Carvalho, I.T., Santos, L., Antibiotics in the aquatic environments: A review of the European scenario, Environ. Int. 94, 736-757, 2016.

5. Albero, B., Sánchez-Brunete, C., García-Valcárcel, A.I., Ultrasound-assisted extraction of emerging contaminants from environmental samples, TrAC Trends Anal. Chem. 71, 110-118, 2015.

6. Bellenger, J.P., Cabana, H., Emerging contaminants: a scientific challenge without borders, Sci. Total Environ. 487, 747, 2014.

7. Krzeminski, P., Tomei, M.C., Karaolia, P., Langenhoff, A., Almeida, C.M.R., Felis, E., Rizzo, L., Performance of secondary wastewater treatment methods for the removal of contaminants of emerging concern implicated in crop uptake and antibiotic resistance spread: a review, Sci. Total Environ. 648, 10521081, 2018.

8. EC, Directive 2000/60/EC of the European Parliament and of the Council of 23 October 2000 establishing a framework for Community action in the field of water policy. Off J. Eur. Parliam. L 327, 1-82, 2000.

9. EC, Decision No 2455/2001/EC of the European Parliament and of the Council of 20 November 2001 establishing the list of priority substances in the field of water policy and amending Directive 2000/60/EC. Off J. Eur. Commun. L 331, 1-5, 2001.

10. EC, Directive 2008/105/EC of the European Parliament and of the Council of 16 December 2008 on environmental quality standards in the field of water policy, amending and subsequently repealing Council Directives 82/176/EEC, 83/513/EEC, 84/156/EEC, 84/491/EEC. Off J. Eur. Union L 348, 84-97, 2008.

11. EC, Directive 2013/39/EU of the European Parliament and of the Council of 12 August 2013 amending Directives 2000/60/EC and 2008/105/EC as regards priority substances in the field of water policy. Off J. Eur. Union L 226, 1-17, 2013.

12. EC, Decision (EU) 2015/495 of 20 March 2015 establishing a watch list of substances for Union-wide monitoring in the field of water policy pursuant to Directive 2008/105/EC of the European Parliament and of the Council. Off J. Eur. Parliam. L 78, 40-42, 2015.

13. Chitescu, C.L., Kaklamanos, G., Nicolau, A., Stolker, M., High sensitive multiresidue analysis of pharmaceuticals and antifungals in surfacewater using U-HPLC-Q-Exactive Orbitrap HRMS, Application to the Danube river basin on the Romanian territory., Sci. Total Environ. 532, 501-511, 2015.

14. Bănăduc, D., Rey, S., Trichkova, T., Lenhardt, M., Curtean-Bănăduc, C., The Lower Danube RiverDanube Delta-NorthWest Black Sea: A pivotal area of major interest for the past, present and future of its fish fauna - A short review, Sci Total Environ. 545-546, 137-151, 2016.

15. Arditsoglou, A., Voutsa, D., Occurrence and partitioning of endocrine-disrupting compounds in the marine environment of Thermaikos Gulf, Northern Aegean Sea, Greece, Mar. Pollut. Bull. 64, 2443-2452, 2012.

16. Borova, B.V., Maragou, N.C., Gago-Ferrero, P., Pistos, C.,Thomaidis, N.S., Highly sensitive determination of 68 psychoactive pharmaceuticals, illicit drugs, and related human metabolites in wastewater by liquid chromatography-tandem mass spectrometry, Anal Bioanal Chem, 406, 4273-4285, 2016.

17. Papageorgiou, M., Kosma, C., Dimitra Lambropoulou, D., Seasonal occurrence, removal, mass loading and environmental risk assessment of 55 pharmaceuticals and personal care products in a municipal wastewater treatment plant in Central Greece, Sci. Total Environ. 543, 547-569, 2016.

18. Moldovan, Z., Marincas, O., Povar, I., Lupascu, T., Longree, P., Rota, J. S., Alder, A. C., Environmental exposure of anthropogenic micropollutants in the Prut River at the Romanian-Moldavian border: a snapshot in the lower Danube river basin, Environ. Sci. Pollut. Res. Int. 25(31), 31040-31050, 2018. 
19. Fekadu, S., Alemayehu, E., Dewil, R., Van der Bruggen, B., Pharmaceuticals in freshwater aquatic environments: A comparison of the African and European challenge. Sci. Total Environ. 654, 324-337, 2019.

20. Szymańska U., Wiergowski M., Sołtyszewski I., Kuzemko J., Wiergowska G., Woźniak M.K., Presence of antibiotics in the aquatic environment in Europe and their analytical monitoring: Recent trends and perspectives, Microchemical Journal 147, 729-740, 2019.

21. Kumar M., Jaiswal S., Sodhi K.K., Shree P., Singh D.K., Agrawal P.K., Shukla P., Antibiotics bioremediation: Perspectives on its ecotoxicity and resistance, Environ. Int. 124, 448-461, 2019.

22. Mansell, D.S., Bryson, R.J., Harter, T., Webster, J.P., Kolodziej, E.P., Sedlak, D.L., Fate of endogenous steroid hormones in steer feedlots under simulated rainfall-induced runoff, Environ. Sci. Technol. 45, 8811$8818,2011$.

23. Jarošová, B., Javůrek J., Adamovský, O., Hilscherová, K., Phytoestrogens and mycoestrogens in surface waters-Their sources, occurrence, and potential contribution to estrogenic activity, Environ. Int. 81, 26-44, 2015.

24. Ohore, O.E., Zhang, S., Endocrine disrupting effects of bisphenol A exposure and recent advances on its removal by water treatment systems. A review, Scientific African 5, e00135, 2019.

25. Toner, F., Allan, G., Dimond, S.S., Waechter, J.M., Beyer, D., In vitro percutaneous absorption and metabolism of bisphenol a (BPA) through fresh human skin, Toxicol. Vitr. 47, 147-155, 2018.

26. Hines, C.J., Jackson, M.V., Christianson, A.L., Clark, J.C., Arnold, J.E., Pretty, J.R., Deddens, J.A., Air, hand wipe, and surface wipe sampling for bisphenol a (BPA) among workers in industries that manufacture and use BPA in the United States, J. Occup. Environ. Hyg. 14, 882-897, 2017.

27. Enachi E., Chițescu C., Bahrim G., Ene A., Monitoring of emerging pollutants from aquatic ecosystems antibiotics, endocrine disruptors and contraceptives, Abstract book MONITOX International Symposium "Deltas and Wetlands" September 15-17, 2019, Tulcea, Romania, Paper S1.13, Editura C.I.T.D.D, pp. 3233, 2019. 